\title{
Effect of Catalyst Composition on Si Nanowire Growth Kinetics
}

\author{
S. Kodambaka, ${ }^{*}$ J. Tersoff, ${ }^{* *}$ C.-Y. Wen, ${ }^{* * *}$ M.C. Reuter, ${ }^{* *}$ E.A. Stach, ${ }^{* * *}$ and F.M. Ross ${ }^{* *}$ \\ * Department of Materials Science and Engineering, University of California Los Angeles, Los \\ Angeles, CA 90095 \\ ** IBM T.J. Watson Research Center, Yorktown Heights, NY 10598 \\ *** Purdue University, School of Materials Engineering and Birck Nanotechnology Center, West \\ Lafayette, IN
}

$\mathrm{Si}$ and Ge nanowires have recently received renewed attention owing to their significantly enhanced energy storage (Li ion batteries) and energy generation (thermoelectrics) properties.[1-5] Nanowires are attractive due to their potential for the formation of single-crystalline, defect-free, heterostructure devices structures with controlled electronic and optical properties. The challenge, however, is the large-scale fabrication of materials with precisely controlled composition, structure, and morphology.

$\mathrm{Si}$ and Ge nanowires are most commonly grown via vapor-liquid-solid (VLS) process using $\mathrm{Au}$ as the catalyst, although other metals (e.g., $\mathrm{Ag}, \mathrm{Al}, \mathrm{Cu}, \mathrm{Ga}, \mathrm{In}, \mathrm{Mn}, \mathrm{Ni}, \mathrm{Pd}, \mathrm{Pt}$, and $\mathrm{Ti}$ ) and variants of VLS method, such as vapor-solid-solid (VSS) process have been used. [6] During VLS (or VSS), material from the vapor phase is preferentially deposited in the form of a wire at the wirecatalyst interface. Recent studies indicate that VLS growth of Si/Ge heterostructured nanowires using $\mathrm{Au}$ as the catalyst leads to diffuse interfaces. [7] Controlling the interfacial abruptness is a challenging task that depends sensitively on the catalyst state and composition. Therefore, we explore the possibility of using alloy catalysts to grow nanowires. As a first step, we study the kinetics of Si nanowire growth using Au-Al as the catalyst.

Using in situ transmission electron microscopy (TEM), we directly observe the growth of Si nanowires disilane as the $\mathrm{Si}$ source gas and $\mathrm{Au}-\mathrm{Al}$ as the catalyst. Growth experiments are carried out on clean $\mathrm{Si}(111)$ substrates. First, we deposit a few monolayers of Al followed by Au. The samples are then transferred to the TEM chamber and growth is initiated by heating the samples in presence of disilane gas. Bright-field TEM images are recorded at video rate (30 frames/s) during growth as a function of temperature, pressure, and time. For the $\mathrm{Au}-\mathrm{Al} / \mathrm{Si}$ system, we find that the VLS growth of nanowires occurs at relatively higher temperatures $\left(\sim 500{ }^{\circ} \mathrm{C}\right)$ than that is required in $\mathrm{Au} / \mathrm{Si}$ system. Presence of Al leads to the growth of narrower wires with smoother surfaces. Interestingly, we observe VSS growth at lower temperatures. Our observations indicate that the catalyst composition and its state can significantly alter the nanowire growth kinetics and hence growth morphologies and structures. These results may help develop methods to synthesize nanowires with tunable morphologies and compositions.

*work done at the IBM T.J. Watson Research Center

References

[1] Tian, B., Zheng, X., Kempa, T.J., Fang, Y., Yu, N., Yu, G., Huang, J. and Lieber, C.M., "Coaxial silicon nanowires as solar cells and nanoelectronic power sources," Nature 449, 885890 (2007). 
[2] Hochbaum, A.I., Chen, R., Delgado, R.D., Liang, W., Garnett, E.C., Najarian, M., Majumdar, A. and Yang P., "Enhanced thermoelectric performance of rough silicon nanowires," Nature 451, 163-167 (2008).

[3] Boukai, A.I., Bunimovich. Y., Tahir-Kheli, J., Yu, J.-K., Goddard III, W.A. and Heath, J.R., "Silicon nanowires as efficient thermoelectric materials," Nature 451, 168-171 (2008).

[4] Chan, C.K., Peng, H., Liu, G., McIlwrath, K., Zhang, X.F., Huggins, R.A. and Cui, Y., "Highperformance lithium battery anodes using silicon nanowires," Nature Nanotechnology 3, 31-35 (2008).

[5] Chan, C.K., Zhang, X.F. and Cui, Y., "High capacity Li ion battery anodes using Ge nanowires," Nano Lett. 8, 307-309 (2008).

[6] Givargizov, E.I., [Highly Anisotropic Crystals], Springer-Verlag, New York, 70-229 (1987).

[7] Clark, T.E., Nimmatoori, P., Lew, K.-K., Pan, L., Redwing, J.M. and Dickey, E.C., "Diameter Dependent Growth Rate and Interfacial Abruptness in Vapor-Liquid-Solid $\mathrm{Si} / \mathrm{Si}_{1-\mathrm{x}} \mathrm{Ge}_{\mathrm{x}}$ Heterostructure Nanowires," Nano Lett. 8, 1246-1252 (2008).

[8] SK gratefully acknowledges the financial support from the University of California Energy Institute (UCEI) and the UCLA Faculty Grants Program. 